\title{
Períodos de Interferência de Plantas Daninhas na Cultura do SORgo ForRageIro EM TERRAS BAIXAS ${ }^{1}$
}

\author{
Periods of Weed Interference in Sorghum Grown Under Lowland Conditions
}

\begin{abstract}
ANDRES, A. ${ }^{2}$, CONCENÇO, G. ${ }^{3}$, SCHWANKE, A.M.L. ${ }^{4}$, THEISEN, G. ${ }^{2}$ e MELO, P.T.B.S. ${ }^{5}$
RESUMO - Objetivou-se com este trabalho avaliar a eficiência do método mecânico de controle de plantas daninhas na cultura do sorgo e determinar o período crítico de competição da cultura com a comunidade infestante em terras baixas de clima temperado, considerando o estádio de desenvolvimento das plantas de sorgo. O experimento foi instalado em condições de campo, em Planossolo hidromórfico cultivado nos últimos cinco anos com arroz, com população elevada de plantas daninhas, principalmente capim-arroz (Echinochloa sp.) e papuã (Brachiaria plantaginea). Os tratamentos consistiram de diferentes periodos de convivência das plantas daninhas com a cultura ou de manutenção da cultura no limpo. Esses períodos foram da emergência até o sorgo atingir três, cinco, sete e nove folhas. Foram mantidas, ainda, uma testemunha constantemente limpa e uma permanentemente infestada. Concluiuse que o controle das plantas daninhas na cultura do sorgo, cultivado em terras baixas de clima temperado, deve ser realizado no período entre a emissão da terceira e a da sétima folha, podendo-se utilizar com segurança o controle mecânico para esse fim, sem prejuizos no rendimento de grãos da cultura.
\end{abstract}

Palavras-chave: arroz vermelho, capim-arroz, competição.

\begin{abstract}
The objective of this work was to evaluate the efficiency of the mechanical method of weed control in sorghum crop, and to determine the critical period of competition between weeds and the culture under lowland fields in temperate climate areas, considering the development stage of the sorghum plants. The trial was installed under field conditions, in lowland where flooded rice had grown in the previous five years, with high infestation levels of barnyardgrass (Echinochloa sp.) and alexandergrass (Brachiaria plantaginea). The treatments were intercropping periods or absence of weeds in the experimental unitis. These periods were from emergence until the crop stage of 3, 5, 7 or 9 completely expanded leaves. Besides the treatments that involved the presence or absence of weeds, there were one control always free of infestation and one with no weed control. It was concluded that weed control in the sorghum crop, grown in lowland fields of temperate climate areas, should be conducted between the emission of the third and the seventh leaves of the crop, with the adoption of mechanical control being viable for this objective, with no damage for the sorghum grain yield.
\end{abstract}

Keywords: red rice, barnyardgrass, competition.

\section{INTRODUÇÃO}

Em terras baixas, o fator limitante à utilização do sistema de rotação de culturas é o excesso de umidade, devido à dificuldade de drenagem do solo (FEPAGRO, 2005). Nesse ambiente, pesquisa-se a viabilidade do cultivo de milho, soja ou sorgo em rotação com o arroz irrigado (Andres et al., 2001). No entanto, em anos com alta precipitação pluvial, os cultivos de soja ou milho podem ser seriamente afetados (FEPAGRO, 2005).

Recebido para publicação em 29.8.2007 e na forma revisada em 5.6.2009.

2 Pesquisador de Herbologia da Embrapa Clima Temperado, BR 392 km 78, Caixa Postal 403, 96001-970 Pelotas-RS, <andre@cpact.embrapa.br>; ${ }^{3}$ Doutor em Fitotecnia, International Agronomist - Valmont Industries - USA; ${ }^{4}$ Mestre em Manejo e Controle de Plantas Daninhas, Departamento de Fitossanidade, Universidade Federal de Pelotas, Pelotas-RS, ${ }^{5}$ Mestre em Sementes, Doutor em Fitotecnia pela FAEM/UFPel, extensionista da PMP, Pelotas-RS. 
A opção pela rotação do arroz irrigado com as espécies ditas "de sequeiro" (milho, soja e sorgo), além de diversificar a produção de grãos nessas áreas, proporciona a possibilidade de rotação de princípios ativos e a redução da pressão de seleção de biótipos de plantas daninhas resistentes na cultura do arroz irrigado (Andres et al., 2007), contribuindo ainda para redução da presença de arroz-vermelho e capim-arroz no banco de sementes do solo pela adoção de métodos de controle eficientes, modificações das condições de solo e utilização de herbicidas seletivos para a cultura (Erasmo et al., 2004; SOSBAI, 2005; Sánchez-Olquín et al., 2007). Além disso, o sorgo apresenta maior tolerância ao encharcamento que o milho e a soja e se adapta com certa facilidade às condições de várzeas, com menores prejuízos, por suportar o encharcamento do solo por períodos maiores que o milho e a soja (Raupp, 2000; Chielle et al., 2000). Em condições de deficiência ou excesso hídrico do solo, as variedades de sorgo silageiro encontram condição mais favorável de produção em relação à maioria das culturas.

A eficiência de métodos de controle de plantas daninhas é fundamental para o sucesso da diversificação de culturas em várzeas. A prática de capina manual poderia ser alternativa viável no combate das plantas daninhas na cultura do sorgo em áreas de pequenos produtores, onde se dá preferência à utilização dos recursos já existentes na propriedade (Kathiresan, 2007).

O periodo em que a lavoura necessita ficar mantida livre da infestação de invasoras, sob ameaça de comprometimento da produtividade, é conhecido como Período Crítico de Prevenção à Interferência - PCPI. A determinação do período crítico pode ser feita considerandose os estádios fenológicos dos genótipos ou em períodos de tempo (Chhokar \& Balyan, 1999; Amador-Ramírez, 2002). Para o sorgo, o estádio fenológico da cultura é normalmente adotado, pois o número de dias após a emergência é variável em função de uma série de fatores, tanto bióticos como abióticos (Larcher, 2000).

O manejo integrado de plantas daninhas combina as diversas práticas de controle, sendo as mais importantes as capinas e os métodos mecânicos ou químicos, feitas no momento adequado (Freitas et al., 2004). É conhecida a eficiência do controle mecânico de plantas daninhas, porém são reduzidas as informações sobre número de operações necessárias para evitar a competição de invasoras no cultivo de sorgo em terras baixas de clima temperado, assim como a determinação do período crítico de competição desta cultura com as plantas daninhas nesse ambiente, visando evitar operações desnecessárias de controle mecânico, que poderiam acarretar maior custo e maiores danos mecânicos às plantas da cultura, ocasionando perdas na produção final (Freitas et al., 2006).

Com base no exposto, objetivou-se com este trabalho avaliar a eficiência do método mecânico de controle de plantas daninhas e determinar o período crítico de prevenção à interferência das plantas invasoras na cultura do sorgo forrageiro.

\section{MATERIAL E MÉTODOS}

O experimento foi instalado em condições de campo, em Planossolo hidromórfico eutrófico solódico, unidade de mapeamento Pelotas (Andres et al., 2001). A área foi cultivada nos últimos cinco anos com arroz, apresentando população elevada de plantas daninhas, principalmente capim-arroz (Echinochloa sp.) e papuã (Brachiaria plantaginea). A avaliação da contribuição de cada espécie presente para a infestação da área foi realizada sistematicamente no momento da aplicação dos tratamentos, por escala visual, sendo os valores expressos em percentual de cobertura da área experimental, como a média das quatro avaliações (Figura 1). O preparo do solo e o manejo da cultura no sistema convencional foram realizados conforme as recomendações técnicas para a cultura do sorgo. Utilizou-se o híbrido BRS 305, semeado com espaçamento entre linhas de $0,50 \mathrm{~m}$ e densidade de 10 sementes por metro, utilizando semeadora-adubadora SHM-1113, com cinco linhas. A emergência ocorreu nove dias após a semeadura. A adubação de base consistiu na aplicação de $400 \mathrm{~kg} \mathrm{ha}^{-1}$ da formulação organomineral 04-12-08, com 25\% de matéria orgânica. Para adubação em cobertura, foram aplicados $150 \mathrm{~kg} \mathrm{ha}^{-1}$ de $\mathrm{N}$ na forma amídica, parcelada em três ocasiões (plantas de sorgo com quatro, seis e oito folhas definitivas), em aplicações direcionadas na linha. 


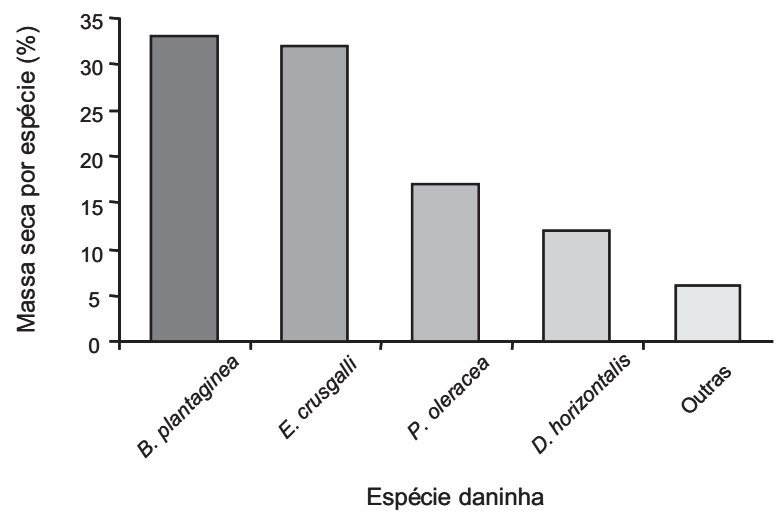

Figura 1 - Participação percentual aproximada das principais plantas daninhas na comunidade infestante. Na categoria "outras" incluem-se Aeschynomene sp. e Cyperus sp.

O delineamento experimental foi de blocos ao acaso com quatro repetições. As unidades experimentais mediram $3 \times 5 \mathrm{~m}\left(15 \mathrm{~m}^{2}\right)$, compreendendo cinco linhas de sorgo, sendo a área útil de $8,4 \mathrm{~m}^{2}(2,1 \times 4 \mathrm{~m})$. Os tratamentos foram constituídos de dois grupos complementares, com convivência e com controle. No grupo com convivência, a cultura permaneceu com interferência das plantas daninhas por diferentes fases do seu ciclo: até três, cinco, sete ou nove folhas. No grupo com controle, a cultura permaneceu livre da interferência das plantas daninhas até três, cinco, sete ou nove folhas das plantas de sorgo, sendo essas parcelas mantidas infestadas a partir desse periodo. Foram mantidas, ainda, uma testemunha constantemente limpa (com capinas semanais) e uma constantemente com convivência. As capinas, quando requeridas pelo tratamento, foram realizadas nas entrelinhas, sendo as plantas daninhas da linha de semeadura de sorgo removidas manualmente.

Ao final do ciclo da cultura foram avaliados o número de panículas de sorgo por $\mathrm{m}^{2}$, a massa de panículas e o rendimento de grãos por hectare. O número de panículas por $\mathrm{m}^{2}$ foi obtido pela contagem de todas as panículas de sorgo contidas na área útil da parcela, após a eliminação das plantas consideradas como bordadura da unidade experimental. Essas panículas foram cortadas, acondicionadas em sacos de aniagem e colocadas para secar em casa de vegetação com circulação natural de ar, protegidas da incidência da luz solar direta. Após sete dias de secagem, as panículas tiveram a massa aferida, sendo os grãos destacados da panícula e sua massa e umidade aferidas para obtenção do rendimento de grãos por hectare.

Os resultados foram verificados quanto à normalidade e homogeneidade e submetidos à análise de variância pelo teste $\mathrm{F}$ a $5 \%$ de probabilidade. No caso de significância estatística, foi efetuada comparação múltipla de médias entre tratamentos pelo teste de Duncan a 5\% de probabilidade para todas as variáveis, bem como análise de regressão linear para os grupos de tratamentos com períodos iniciais de convivência e de controle, de forma a estabelecer o período crítico de prevenção à interferência.

\section{RESULTADOS E DISCUSSÃO}

As plantas infestantes predominantes na área experimental (Figura 1) foram o papuã (Brachiaria plantaginea) e o capim-arroz (Echinochloa crusgalli), cujos altos niveis de infestação e característica de metabolismo $\mathrm{C}_{4}$ as tornam altamente competitivas com as plantas da cultura, em razão principalmente do rápido crescimento e da capacidade de sombreamento já nos estádios iniciais de desenvolvimento (Larcher, 2000).

Os períodos de controle ou convivência não resultaram em diferenças quanto ao número de panículas, independentemente da extensão de cada período. Por outro lado, na testemunha mantida sem controle durante todo o ciclo da cultura o número de panículas foi menor que o encontrado no tratamento sempre livre de competição. Verificou-se ainda que os tratamentos com capinas semanais que se estenderam até que as plantas de sorgo se encontrassem com três ou cinco folhas apresentaram menor número de panículas em relação ao tratamento mantido livre de infestação durante todo o ciclo (Tabela 1).

A massa de panículas aumentou conforme as capinas foram prolongadas a partir da emergência das plantas (períodos de controle) e também conforme foram iniciadas mais cedo e mantidas até o final do ciclo (períodos de convivência). A testemunha sempre infestada mostrou resultados similares aos dos tratamentos com capina até que as plantas de sorgo atingissem três ou cinco folhas desenvolvidas (Tabela 1). Capinas realizadas com plantas de sorgo a partir do estádio de nove folhas se 
Tabela 1 - Número e massa de panículas por metro quadrado e rendimento de grãos de sorgo por hectare, em função dos períodos iniciais de convivência e de controle das plantas daninhas, em condição de campo na cultura do sorgo

\begin{tabular}{|l|c|c|c|}
\hline \multicolumn{1}{|c|}{ Tratamento } & Panículas m & $\begin{array}{c}\text { Massa } \\
\text { Panícula } \\
(\mathrm{g})\end{array}$ & $\begin{array}{c}\text { Rendimento } \\
\left(\mathrm{kg} \mathrm{ha}^{-1}\right)\end{array}$ \\
\hline 1. Controle até 3 folhas & $15,5 \mathrm{bc}$ & $29,3 \mathrm{c}$ & $4.199 \mathrm{c}$ \\
\hline 2. Controle até 5 folhas & $15,8 \mathrm{bc}$ & $30,0 \mathrm{c}$ & $5.017 \mathrm{bc}$ \\
\hline 3. Controle até 7 folhas & $18,8 \mathrm{abc}$ & $98,4 \mathrm{ab}$ & $8.480 \mathrm{a}$ \\
\hline 4. Controle até 9 folhas & $19,0 \mathrm{abc}$ & $90,4 \mathrm{ab}$ & $7.816 \mathrm{a}$ \\
\hline 5. Convivência até 3 folhas & $20,3 \mathrm{abc}$ & $85,4 \mathrm{ab}$ & $8.111 \mathrm{a}$ \\
\hline 6. Convivência até 5 folhas & $21,0 \mathrm{ab}$ & $71,8 \mathrm{~b}$ & $7.198 \mathrm{ab}$ \\
\hline 7. Convivência até 7 folhas & $20,3 \mathrm{abc}$ & $39,8 \mathrm{~b}$ & $5.390 \mathrm{bc}$ \\
\hline 8. Convivência até 9 folhas & $19,5 \mathrm{abc}$ & $12,1 \mathrm{c}$ & $1.638 \mathrm{~d}$ \\
\hline 9. Capinas semanais & $24,8 \mathrm{a}$ & $89,4 \mathrm{ab}$ & $8.745 \mathrm{a}$ \\
\hline 10. Testemunha infestada & $13,8 \mathrm{c}$ & $20,7 \mathrm{c}$ & $1.046 \mathrm{~d}$ \\
\hline
\end{tabular}

Médias seguidas de letras iguais, na mesma coluna, não diferem pelo teste de Duncan a $5 \%$ de probabilidade.

mostraram sem nenhum efeito positivo na massa de panículas, com resultado estatisticamente semelhante ao observado na testemunha sempre infestada.

A capina manual de lavouras de sorgo é um método amplamente utilizado em pequenas propriedades. Normalmente, o pequeno produtor utiliza duas a três capinas com enxada durante os primeiros 40 a 50 dias da lavoura (Rodrigues et al., 2000). A partir daí, o crescimento do sorgo contribuirá para a redução das condições favoráveis à germinação, crescimento e desenvolvimento das plantas daninhas, principalmente pela redução da radiação incidente (Rizzardi et al., 2001).

O rendimento de grãos da cultura também se situou em nível superior quando a capina se estendeu por maior período, ou quando foi iniciada mais cedo e mantida até o final do ciclo. De maneira geral, pode-se observar que, quando as capinas semanais foram conduzidas até que as plantas de sorgo atingissem sete folhas completamente desenvolvidas, a produção não foi afetada quando comparada à testemunha sempre livre de infestação. Da mesma forma, quando as capinas foram realizadas semanalmente a partir do estádio de cinco folhas das plantas de sorgo e mantidas até o final do ciclo, o rendimento de grãos foi estatisticamente semelhante ao da testemunha sempre livre de infestação.
Segundo o modelo proposto por Bleasdale (1960), adaptado por Pitelli (1985), o grau de interferência das plantas daninhas nas culturas depende de fatores ligados à própria cultura (espécie cultivada, cultivar ou variedade e espaçamento), à comunidade infestante (composição específica, densidade e distribuição), ao ambiente (clima, solo e manejo da cultura) e ao período em que elas convivem. Nesse processo, os fatores mais facilmente controláveis, na prática, são a época e a extensão do período de convivência entre culturas e plantas daninhas. Daí a importância da determinação do período em que a cultura deve permanecer livre das plantas daninhas.

No presente trabalho, considerando perda admissivel de produtividade em torno de $5 \%$, o PAI compreendeu o periodo entre a emergência da cultura e a emissão da terceira folha; o PCPI, entre a emissão da terceira e da sétima folha; e o PTPI, entre a emergência e a emissão da sétima folha (Figura 2). Deve-se ressaltar, no entanto, que esses periodos podem variar principalmente em função do potencial competitivo das espécies daninhas presentes, da densidade em que estas se encontram e das condições ambientais predominantes, que podem ou não ser favoráveis a essas plantas daninhas. Feltner et al. (1973) concluíram que Abutilon theophrasti foi sempre mais competitiva que

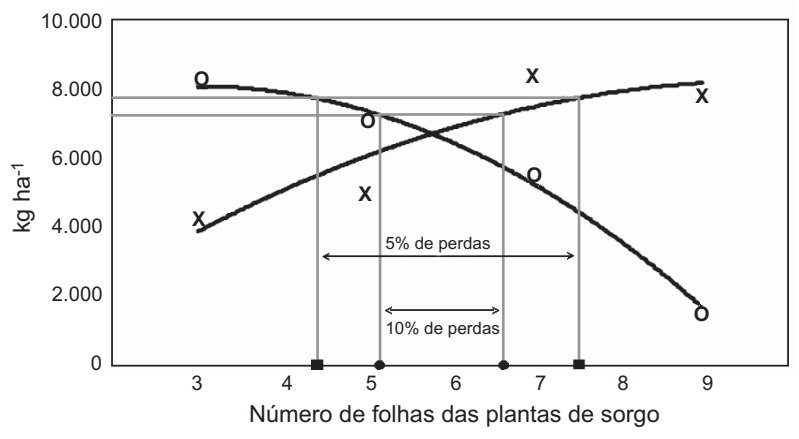

Figura 2 - Rendimento de grãos de sorgo, em função dos períodos iniciais de controle e de convivência das plantas daninhas na cultura do sorgo cv. BRS 305 em terras baixas de clima temperado. ( $\mathbf{x}$ ) períodos iniciais de controle; o) períodos iniciais de convivência. Período em que a cultura deve permanecer livre da competição com plantas daninhas para que ocorra em torno de $5 \%(\square)$ ou $10 \%(\bullet)$ de perdas no rendimento de grãos ao final do ciclo da cultura. Equações: Controle $\left(\mathrm{y}=-92,6 \mathrm{x}^{2}+1827 \mathrm{x}-787 \quad \mathrm{R}^{2}=0,82\right)$; Convivência $\left(y=-177,4 x^{2}+1067 x+6451 \quad R^{2}=0,99\right)$ 
Ipomoea purpurea e I. hederacea quando competindo com plantas de sorgo, mas o período de competição variou em função do nível de umidade do solo e de adubação nitrogenada. Salienta-se que a consideração do número de folhas da cultura normalmente é muito mais efetiva que a do período em dias após a emergência, sobretudo por este último variar muito em função dos fatores bióticos e abióticos, como previamente comentado. Dessa forma, optou-se por não associar o período em dias após a emergência ao estádio fenológico da cultura.

A análise de regressão polinomial evidencia que há prejuízos na produção com o atraso da retirada das plantas daninhas da área (Figura 2). Os tratamentos que corresponderam a capinas realizadas nos estádios fenológicos da cultura de sorgo com cinco, sete ou nove folhas proporcionaram produção relativa ao redor de $88,7,66,5$ e $20,2 \%$ do observado no tratamento de capina a partir das três folhas, respectivamente (Figura 2). O tratamento capinado até nove folhas e o com capinas a partir de três folhas foram idênticos à testemunha sempre livre de infestação (Tabela 1). Quando se realizaram capinas até três, cinco, sete ou nove folhas de sorgo, observou-se que nos dois primeiros momentos de capina o rendimento relativo obtido foi de 51,5 e $61,6 \%$, respectivamente para capina com três e cinco folhas de sorgo, em relação à média dos dois últimos.

Logo, pode-se estimar que, se a lavoura permanecer livre de competição com as plantas daninhas entre a emissão da quarta e da sétima folhas, as perdas máximas estimadas serão iguais ou inferiores a $5 \%$ da produção obtida se a lavoura permanecesse livre de competição durante todo o ciclo. Da mesma forma, se o periodo de controle de plantas daninhas for menor, entre a emissão da quinta e da sétima folhas das plantas de sorgo, as perdas poderão chegar a $10 \%$ do rendimento esperado (Figura 2). Por sua vez, em lavouras de alta tecnologia, as perdas estimadas no rendimento de grãos não devem superar 2 a $3 \%$, e o ideal é que a cultura permaneça livre de plantas daninhas entre a emissão da terceira e da sétima folhas.

A capina manual realizada semanalmente durante todo o ciclo foi eficiente no controle de invasoras e, em valores absolutos, permitiu os melhores resultados de produtividade, mesmo considerando algumas injúrias ocorridas nas plantas durante a capina na entrelinha e o arranque manual na linha. $O$ controle das plantas daninhas na cultura do sorgo, cultivado em terras baixas de clima temperado, deve ser realizado no período entre a emissão da terceira e da sétima folhas, podendo-se utilizar com segurança o controle mecânico para esse fim, sem prejuízos no rendimento de grãos da cultura.

\section{LITERATURA CITADA}

AMADOR-RAMIREZ, M. D. Critical period of weed control in transplanted chilli pepper. Weed Res., n. 42, n. 3 , p. 203-209, 2002.

ANDRES, A. et al. Rotação de culturas e pousio do solo na redução do banco de sementes de arroz vermelho em solo de várzea. R. Bras. Agroci., v. 7, n. 1, p. 85-88, 2001.

ANDRES, A. et al. Detecção da resistência de capim-arroz (Echinochloa sp.) ao herbicida quinclorac em regiões orizícolas do sul do Brasil. Planta Daninha, v.25, n. 1, p. 221-226, 2007.

BLEASDALE, J. K. A. Studies on plant competition. In: HARPER, J. L. (Ed.) The biology of weeds. Oxford: Backwell Scientific Publication, 1960. p. 133-142

CHIELLE, Z.G. et al. Ensaio sul-riograndense de sorgo silageiro 1999/2000, resultados da rede estadual. In: REUNIÃO TÉCNICA ANUAL DO SORGO, 28; REUNIÃO TÉCNICA ANUAL DO MILHO, 45., 2000, Pelotas. Anais... Pelotas: Embrapa Clima Temperado, 2000 p.390-398

CHHOKAR, R. S.; BALYAN, R. S. Competition and control of weeds in soybean. Weed Sci., v. 46, n. 1, p. 301-306, 1999

ERASMO, E. A. L.; PINHEIRO, L. L. A.; COSTA, N. V. Levantamento fitossociológico das comunidades de plantas infestantes em áreas de produção de arroz irrigado cultivado sob diferentes sistemas de manejo. Planta Daninha, v. 22, n. 2, p. 195-201, 2004.

FELTNER, K. C.; VANDERLIP, R. L.; HURST, H. R. Velvetleaf and morningglory competition in grain sorghum. Trans. Kansas Acad. Sci., v. 76, n. 4, p. 282-288, 1973.

FEPAGRO. Indicações técnicas para cultivo de milho e sorgo no Rio Grande do Sul 2005/2006. Porto Alegre: FEPAGRO/EMATER-RS/ASCAR, 2005.

FREITAS, R. S. et al. Períodos de interferência de plantas daninhas na cultura da mandioquinha-salsa. Planta Daninha, v. 22, n. 4 , p. $499-506,2004$

Planta Daninha, Viçosa-MG, v. 27, n. 2, p. 229-234, 2009 
FREITAS, S. P.; RODRIGUES, J. C.; SILVA, C. M. M. Manejo de plantas daninhas no plantio direto da soja (Glycine max) sobre o milheto (Pennisetum maximum). Planta

Daninha, v. 24, n. 3, p. 481-487, 2006.

KATHIRESAN, R. M. Integration of elements of a farming system for sustainable weed and pest management in the tropics. Crop Protec., v. 26, n. 3, p. 424-429, 2007.

LARCHER, W. Ecofisiologia vegetal. São Carlos: RIMA, 2000. $531 \mathrm{p}$.

PITELLI, L. A. Interferência de plantas daninhas em culturas agrícolas. Inf. Agropec., v. 11, p. 16-27, 1985.

RAUPP, A. A. A. Manejo da cultura do sorgo. In: PARFITT, J. M. B. (Ed.). Produção de milho e sorgo em várzea. Pelotas: Embrapa Clima Temperado, 2000. 146 p
RIZZARDI, M. A. et al. Competição por recursos do solo entre ervas daninhas e culturas. Ci. Rural, v. 31, n. 4, p. $707-714,2001$

RODRIGUES, J. A. S.; VERSIANI, R. P.; FERREIRA, M. T. R. Cultivo do sorgo. Sete Lagoas: Embrapa Milho e Sorgo, 2000. Disponível em: <http://sistemasdeproducao cnptia.embrapa.br/FontesHTML/Sorgo/CultivodoSorgo/ index.htm >: Acesso em: 10 jul. 2007.

SÁNCHEZ-OLQUÍN, E.; ARRIETA-ESPINOZA, G.; ESPINOZA-ESQUIVEL, A. M. Vegetative and reproductive development of Costa Rican weedy rice compared with commercial rice (Oryza sativa). Planta Daninha, v.25, n. 1, p. 13-23, 2007.

SOSBAI. Arroz irrigado: recomendações técnicas da pesquisa para o Sul do Brasil. Santa Maria: 2005. 126 p. 